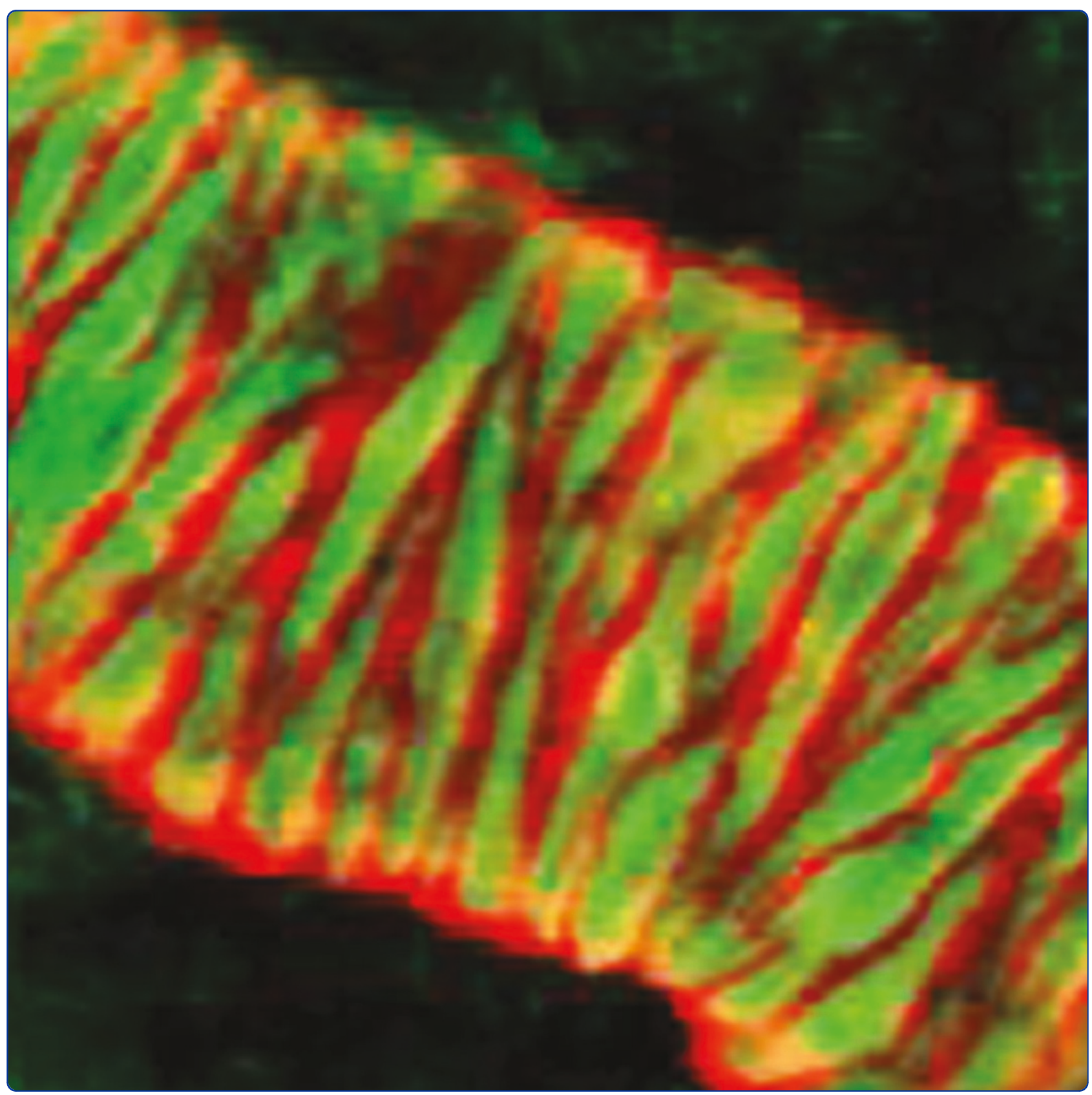

Resorufin analogs preferentially bind cerebrovascular amyloid: potential use as imaging ligands for cerebral amyloid angiopathy

Han et al. 


\title{
Resorufin analogs preferentially bind cerebrovascular amyloid: potential use as imaging ligands for cerebral amyloid angiopathy
}

Byung Hee Han ${ }^{1,2^{*}}$, Meng-liang Zhou ${ }^{1}$, Ananth K Vellimana ${ }^{1}$, Eric Milner ${ }^{1,3}$, David H Kim ${ }^{1}$, Jacob K Greenberg ${ }^{1}$, Wenhua Chu ${ }^{4}$, Robert H Mach ${ }^{4}$ and Gregory J Zipfel ${ }^{1,2,5}$

\begin{abstract}
Background: Cerebral amyloid angiopathy (CAA) is characterized by deposition of fibrillar amyloid $\beta$ (A $\beta$ ) within cerebral vessels. It is commonly seen in the elderly and almost universally present in patients with Alzheimer's Disease (AD). In both patient populations, CAA is an independent risk factor for lobar hemorrhage, ischemic stroke, and dementia. To date, definitive diagnosis of CAA requires obtaining pathological tissues via brain biopsy (which is rarely clinically indicated) or at autopsy. Though amyloid tracers labeled with positron-emitting radioligands such as $\left[{ }^{11} \mathrm{C}\right] \mathrm{PIB}$ have shown promise for non-invasive amyloid imaging in $\mathrm{AD}$ patients, to date they have been unable to clarify whether the observed amyloid load represents neuritic plaques versus CAA due in large part to the low resolution of PET imaging and the almost equal affinity of these tracers for both vascular and parenchymal amyloid. Therefore, the development of a precise and specific non-invasive technique for diagnosing CAA in live patients is desired.

Results: We found that the phenoxazine derivative resorufin preferentially bound cerebrovascular amyloid deposits over neuritic plaques in the aged Tg2576 transgenic mouse model of AD/CAA, whereas the congophilic amyloid dye methoxy-X34 bound both cerebrovascular amyloid deposits and neuritic plaques. Similarly, resorufin-positive staining was predominantly noted in fibrillar $A \beta$-laden vessels in postmortem AD brain tissues. Fluorescent labeling and multi-photon microscopy further revealed that both resorufin- and methoxy-X34-positive staining is colocalized to the vascular smooth muscle (VSMC) layer of vessel segments that have severe disruption of VSMC arrangement, a characteristic feature of CAA. Resorufin also selectively visualized vascular amyloid deposits in live Tg2576 mice when administered topically, though not systemically. Resorufin derivatives with chemical modification at the 7-OH position of resorufin also displayed a marked preferential binding affinity for CAA, but with enhanced lipid solubility that indicates their use as a non-invasive imaging tracer for CAA is feasible.

Conclusions: To our knowledge, resorufin analogs are the fist class of amyloid dye that can discriminate between cerebrovascular and neuritic forms of amyloid. This unique binding selectivity suggests that this class of dye has great potential as a CAA-specific amyloid tracer that will permit non-invasive detection and quantification of CAA in live patients.
\end{abstract}

Keywords: Cerebral amyloid angiopathy, Alzheimer's disease, dementia, diagnosis, amyloid beta, positron emission tomography, amyloid imaging, tracer, resorufin, phenoxazines

\footnotetext{
* Correspondence: hanh@wudosis.wustl.edu

'Department of Neurological Surgery, Washington University School of

Medicine, St. Louis, MO 63110, USA

Full list of author information is available at the end of the article
} 


\section{Background}

Cerebral amyloid angiopathy (CAA) is characterized by amyloid deposition within the walls of leptomeningeal and cortical arterioles. Among the several types of amyloid proteins causing CAA, amyloid $\beta(\mathrm{A} \beta)$ is by far the most common. A $\beta$ comprises several species of 39-43residue peptides (including $A \beta_{1-40}$ and $A \beta_{1-42}$ ) that are produced from amyloid precursor protein (APP) via sequential proteolytic cleavage by $\beta$ - and $\gamma$-secretases [1-3]. Soluble $A \beta$ monomers are produced throughout life; in certain individuals, these aggregate to form insoluble amyloid fibrils. This pathological form of $\mathrm{A} \beta$ is the major constituent of CAA. It is also the primary component of neuritic plaques - one of the pathological hallmarks of Alzheimer's disease (AD). The composition and pathogenesis of vascular vs. parenchymal amyloid deposits, however, have important differences. For example, while $A \beta_{1-42}$ is thought to be an important seed for the formation of both parenchymal plaques and CAA formation $[4,5]$, higher $A \beta_{1-40}$ levels and increased $A \beta_{1-40} / A \beta_{1-42}$ ratios favor formation of CAA over parenchymal plaques in mouse models of AD [6-9].

CAA is primarily a disease of the elderly, with about one-third of individuals aged 60 years or older demonstrating CAA upon postmortem histopathological examination. The incidence of CAA is even higher in patients with $\mathrm{AD}$ since these two conditions share common risk factors. Indeed, up to $90 \%$ of $\mathrm{AD}$ patients have histological evidence of amyloid deposits within cerebral vessels $[10,11]$. Clinically, CAA is a well-recognized cause of "lobar" hemorrhage in the elderly $[12,13]$. Several population-based autopsy studies indicate that CAA is also an independent risk factor for ischemic stroke and dementia [14-18]. To further define the relationship between CAA and its neurological consequences, and to effectively examine novel therapeutics directed against CAA, definitive identification of CAA prior to patient death is critical. Yet, to date, definitive diagnosis of CAA is possible only by direct examination of pathological tissue. Short of obtaining such tissue via brain biopsy, only "possible" or "probable" diagnosis of CAA is achievable through use of the Boston Criteria, which utilize MRI to detect lobar microhemorrhage as an indirect indicator of CAA[19]. This indirect diagnostic technique, however, is limited by its inability to quantify CAA severity and its reliance on cerebral hemorrhage as a surrogate marker for CAA[19]. Development of a noninvasive method for selectively and accurately diagnosing and quantifying CAA would therefore be a major breakthrough for this disease.

Investigation into amyloid-imaging ligands for the diagnosis of $\mathrm{AD}$ and the evaluation of anti-amyloid therapy started more than 10 years ago [20-24]. Fibrillar amyloid-binding dyes such as Congo red, chrysamine G, and thioflavins were investigated as ligands for positron emission tomography (PET) and single photon emission computed tomography (SPECT) imaging of amyloid deposits in $\mathrm{AD}$ patients. Utilizing radiolabeled forms of these molecules, however, was not clinically feasible due to their relative inability to cross the blood-brain barrier (BBB) and their low binding affinities for $A \beta$ aggregates. Since the mid-1990s, many groups have attempted to develop CNS-accessible amyloid ligands derived from those molecules. To date, at least two amyloid tracers $\left[{ }^{11} \mathrm{C}\right]$ PIB $\left(\left[{ }^{11} \mathrm{C}\right] 6-\mathrm{OH}-\mathrm{BTA}-1\right)$ and $\left[{ }^{18} \mathrm{~F}\right]$ florbetapir $\left(\left[\left[{ }^{18} \mathrm{~F}\right]\right.\right.$ AV-45) - have been well characterized. Derived from thioflavin- $T$ and styrylpyridine, respectively, both display favorable amyloid binding profiles, suggesting their great potential as a non-invasive method for early detection of $\mathrm{AD}$ and evaluation of anti-amyloid therapies in $\mathrm{AD}$ patients [25-32]. However, neither dye is appropriate for the specific diagnosis and quantification of CAA due to their lack of selectivity for parenchymal versus cerebrovascular $A \beta$ deposits as well as the low resolution of PET imaging.

During our laboratory's exploration into the effects of CAA deposits on neurovascular architecture and function in aged APP transgenic mice, we serendipitously observed that the fluorescent dye resorufin (7-hydroxy$3 \mathrm{H}$-phenoxazin-3-one) appeared to selectively bind cerebral arterioles bearing congophilic fibrillar amyloid. In this study, we sought to further characterize this unique amyloid binding property of resorufin, and also explore the feasibility of utilizing resorufin and/or its derivatives for CAA-specific amyloid imaging.

\section{Results}

In situ evidence that resorufin preferentially binds CAA in aged Tg2576 mouse brains

Aged Tg2576 mice develop congophilic A $\beta$ aggregates within neuritic plaques throughout the cortex and hippocampus, as well as within cortical leptomeningeal and penetrating arteries [6,33-35]. To determine whether resorufin detects $\mathrm{A} \beta$ aggregates in situ, fixed brain tissues prepared from aged (12-16 mo) Tg2576 mice were co-stained with the Congo red derivative methoxy-X34 and resorufin, followed by fluorescent microscopy (Figure 1). Consistent with previous reports $[33,35]$, we found that methoxy-X34 visualized both cerebrovascular $A \beta$ deposits and neuritic plaques in aged Tg2576 mice (Figure 1A). The fluorescent dye resorufin $\left(E_{x}: 573 \mathrm{~nm}\right.$; $E_{m}: 590 \mathrm{~nm}$ ), however, was found to strongly bind CAA-laden cerebral arterioles but not parenchymal neuritic plaques (Figure 1B). Moreover, resorufin-positive staining was exactly colocalized to methoxy-X34positive staining in CAA-laden vessels (Figure $1 \mathrm{C}$ and 

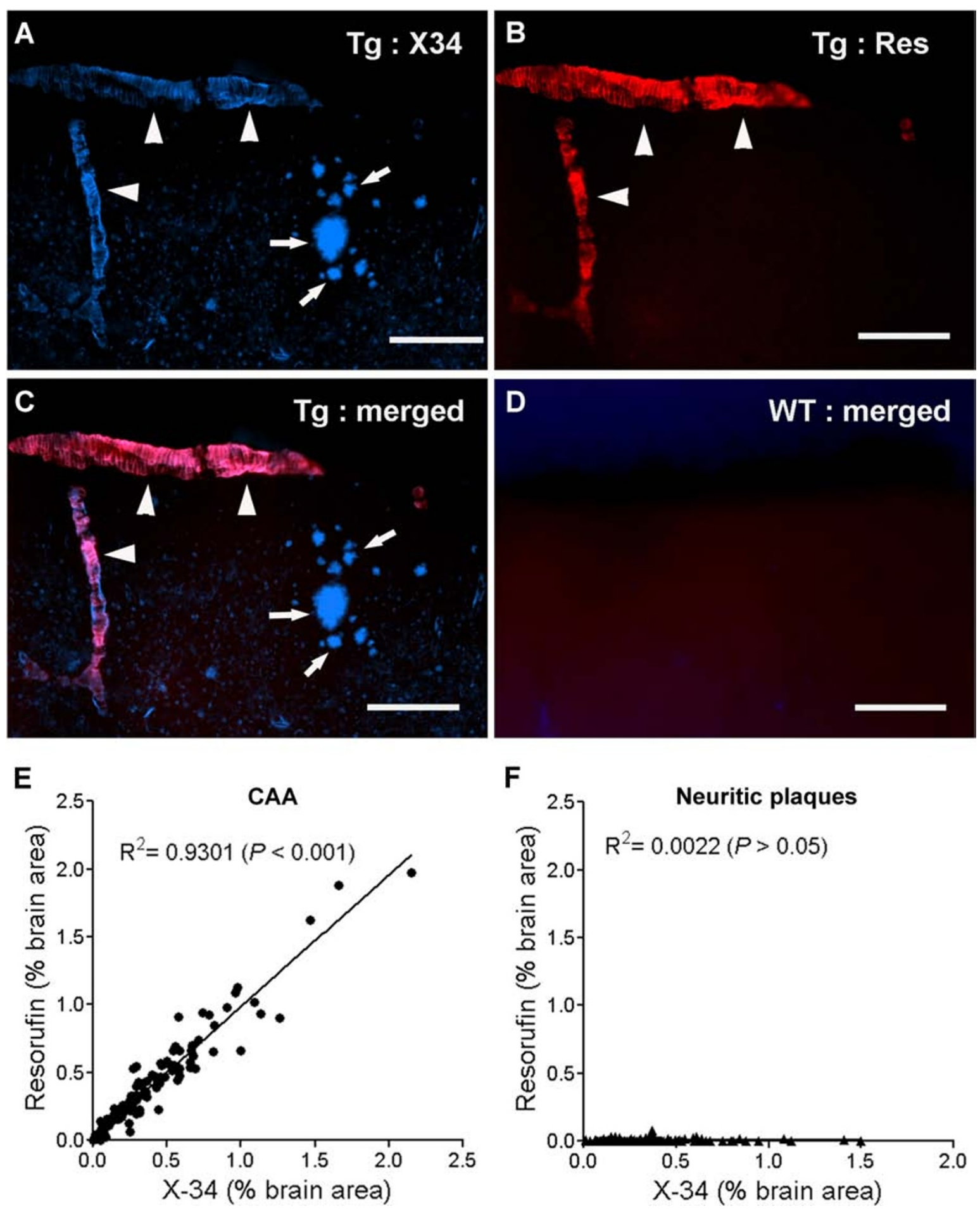

Figure 1 Resorufin preferentially binds CAA in aged Tg2576 brain sections. Paraformaldehyde-fixed brain sections prepared from 16month-old Tg2576 transgenic mice ( $\mathrm{Tg}$ ) or littermate wild-type mice were co-stained with $1 \mu \mathrm{M}$ resorufin (Res) and $2 \mu \mathrm{M}$ methoxy-X34 (X34), followed by fluorescent microscopy ( $N=6-8$ ). Representative images of X34 and resorufin staining in Tg2576 mice (A-C) and wild-type mice (D) are shown. Resorufin selectively binds CAA-laden arterioles (arrowheads) but not senile plaques (arrows), whereas the Congo red derivative methoxy-X34 labels both. Both resorufin and methoxy-X34 staining was absent in age-matched WT mice. Scale bars in A-D: 100 Hm. CAA loads (E) and neuritic plaque loads (F) as determined by methoxy-X34 (X34) staining vs. resorufin staining in the motor cortex of Tg2576 mice were plotted. 
$1 \mathrm{E})$, indicating that resorufin directly interacted with cerebrovascular $A \beta$ aggregates. In contrast, resorufin did not bind methoxy-X34-positive neuritic plaques (Figure $1 \mathrm{C}$ and $1 \mathrm{~F}$ ). Both resorufin and methoxy-X34 reactivity was absent in age-matched wild-type mice (Figure 1D) and in young (6-month-old) Tg2576 mice that do not have fibrillar amyloid deposits (data not shown). These data clearly and directly indicate that resorufin preferentially binds cerebrovascular $A \beta$ aggregates over neuritic plaques in brain sections of aged Tg2576 mice.

\section{Resorufin-positive staining localizes to areas of disrupted vascular integrity in CAA-affected vessels in aged Tg2576 mouse brains}

To explore whether resorufin-positive amyloid deposits influence vascular smooth muscle cell (VSMC) architecture, whole brains from aged Tg2576 transgenic mice and wild-type littermate controls were fixed and subsequently stained with resorufin and the VSMC marker phalloidin-Alexa 488. In line with our previous findings [35], multi-photon microscopy demonstrated that VSMCs were arranged closely in parallel in control mice as well as CAA-free pial arterioles in Tg2576; such vessels (and vessel segments) did not stain with resorufin (Figure 2). However, resorufin- and methoxy-X34-positive $A \beta$ deposits in cerebral vessels were frequently noted in cerebral vessels of aged Tg2576 mice. In these vessels, VSMC arrangement was found to be substantially disrupted - a characteristic feature of CAA.

\section{In situ evidence that resorufin preferentially binds CAA in human AD brains}

We next examined whether resorufin preferentially binds CAA deposits in human AD brains by immunofluorescent labeling. Paraffin-embedded cortical sections were incubated with the anti-A $\beta$ antibody 3D6 followed by staining with resorufin (Figure 3 ). Consistent with our results in Tg2576 mice (Figure 1), marked resorufin-positive staining was noted in the 3D6-positive cerebral arterioles of human AD brains (arrowheads in Figure 3). In contrast, resorufin did not colocalize to 3D6-positive neuritic plaques. Interestingly, resorufinpositive staining was occasionally present in the core of congophilic neuritic plaques (arrows in Figure 3). We also observed that tissues at more advanced stages of CAA pathology (i.e., those with greater numbers of CAA-laden vessels) demonstrated more intense resorufin-positive staining of vessels (data not shown).

\section{In vivo live imaging of CAA amyloid deposits in aged Tg2576 mice}

We observed that intravenous administration of resorufin (up to $50 \mathrm{mg} / \mathrm{kg}$ ) in aged Tg2576 mice (15 mo, i.e., at an age when CAA is highly prevalent) failed to visualize CAA deposits. Instead, the highly fluorescent resorufin remained within the lumen of cerebral blood vessels (data not shown), indicating that resorufin failed to cross the $\mathrm{BBB}$, probably due to its low lipophilicity $\left(\log \mathrm{P}_{\text {oct }}\right)$. We therefore examined whether resorufin was able to selectively visualize CAA deposits in live Tg2576 mice utilizing a closed cranial window preparation with real time imaging-fluorescent microscopy[35]. Topical application of resorufin $(2 \mu \mathrm{M})$ onto the brain surface of aged Tg2576 mice through the cranial window resulted in intense fluorescent labeling within the walls of the leptomeningeal arteries (arrowheads in Figure 4A), but not in neuritic plaques (arrows in Figure 4A). In contrast, topical application of methoxy-X04 labeled A $\beta$ aggregates in both cerebral arteries and parenchymal neuritic plaques (arrowheads and arrows in Figure 4B, respectively). Higher magnification images revealed that both resorufin and methoxy-X04 were colocalized to the vascular smooth muscle cell layer, forming circumferential bands around the vessel (Figure 4D). In contrast, no staining was seen following superfusion of resorufin or methoxy-X04 in age-matched wild-type mice or young Tg2576 mice (data not shown).

\section{Resorufin derivatives with increased lipophilicity demonstrate improved binding affinities for CAA}

Several authors have postulated that moderate lipophilicity $\left(\log \mathrm{P}_{\text {oct }}\right.$ in range of $\left.1-3\right)$ is an essential characteristic of amyloid imaging tracers in order to ensure high initial brain uptake and rapid clearance from the normal brain $[22,36]$. To determine $\log \mathrm{P}_{\text {oct }}$ values of resorufin analogs, octanol-water partition coefficient was examined by fluorometric methods. We found that the acidic compound resorufin had weak lipophilicity $\left(\log \mathrm{P}_{\text {oct }}\right.$ 0.43), while ethoxy- and benzyloxy-resorufin showed increased lipophilicity $\left(\log \mathrm{P}_{\text {oct }}\right.$ values of 1.94 and 2.21 , respectively), indicating more appropriate partition coefficient feasible for amyloid imaging in vivo (Table 1). We then compared the binding affinities of resorufin analogs for CAA deposits versus neuritic plaques in fixed Tg2576 brain tissues utilizing their intrinsic fluorescence (Figure 5). Similar to our results with resorufin (Figure 1), both ethoxy-resorufin and benzyloxy-resorufin preferentially bound CAA-laden vessels but not neuritic plaques in aged Tg2576 mice (Figure 5A). The dissociation constants $\left(K_{D}\right)$ of resorufin and its derivatives were determined by the saturation binding assay performed at various concentrations (Table 2). The binding affinity of resorufin was calculated as $874 \pm 177$ $\mathrm{nM}(n=3)$ on CAA deposits (Figure $5 \mathrm{~B})$, whereas for neuritic plaques it was $>10,000 \mathrm{nM}$ (Figure $5 \mathrm{C}$ ). The binding affinities of ethoxy- and benzyloxy-resorufin for CAA deposits were significantly higher than that of resorufin (ethoxy-resorufin: $K_{D} 247 \pm 135 \mathrm{nM}$; 

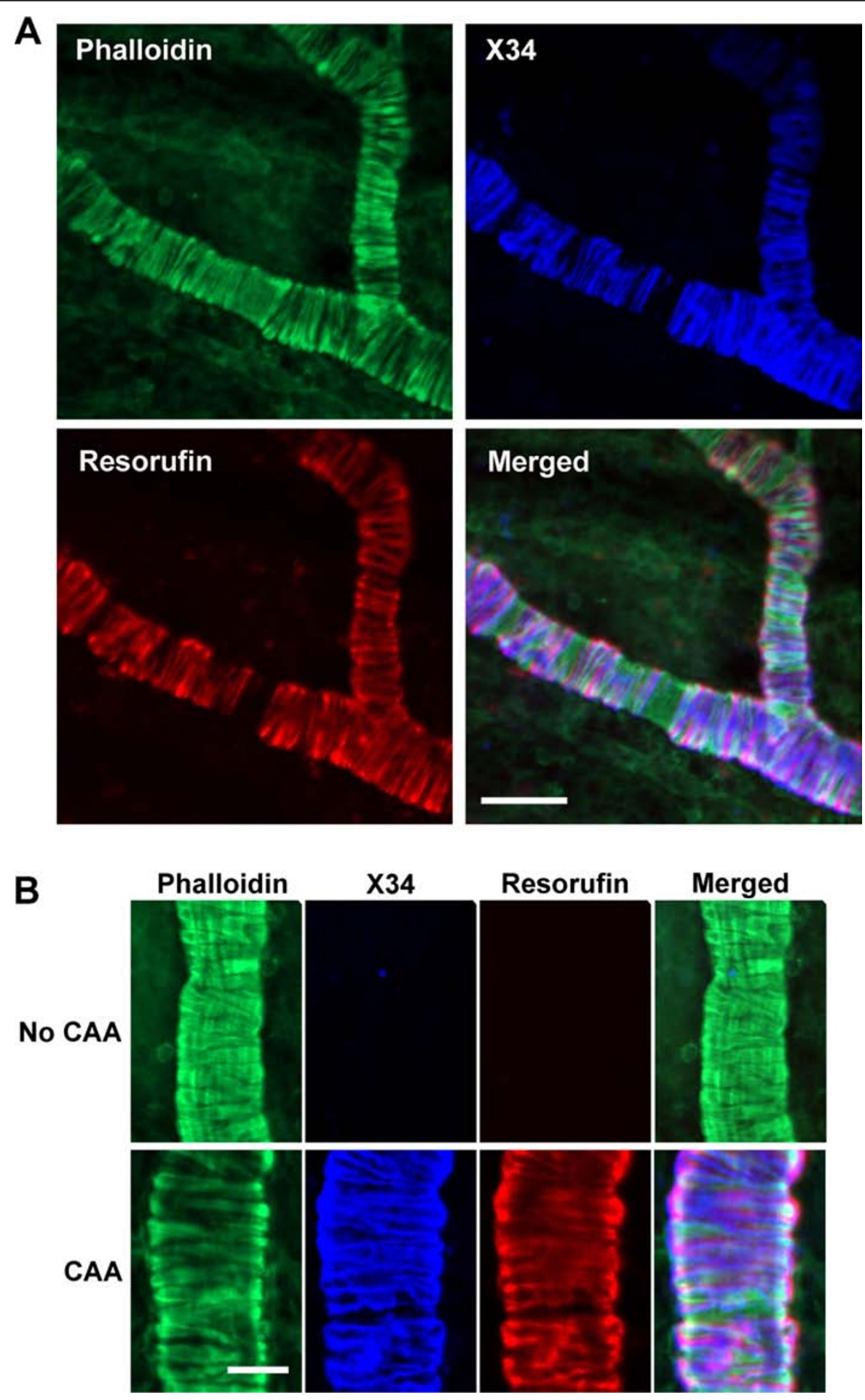

Figure 2 Multi-photon imaging reveals colocalization of resorufin and methoxy-X34 in CAA-affected vessels. Fixed whole brains prepared from aged Tg2576 mice were labeled with a vascular smooth muscle cell (VSMC) marker phalloidin-Alexa 488 (green), and amyloid binding dyes methoxy-X34 (blue) and resorufin (red), followed by imaging by multi-photon microscopy $(n=7)$. A. Representative fluorescent images in the same field demonstrate co-localization of resorufin and X34 staining in the leptomeningeal vessels of aged Tg2576 mice. B. Higher magnification images show that both resorufin and methoxy-X34 are co-localized to the VSMC layer of the vessel segment having severe disruption of VSMC arrangement - a characteristic feature of CAA. In contrast, both methoxy-X34 and resorufin staining is absent in the vessel segment with no CAA pathology. Scale bars, in A: $50 \mu \mathrm{m}$; in B: $25 \mu \mathrm{m}$. 


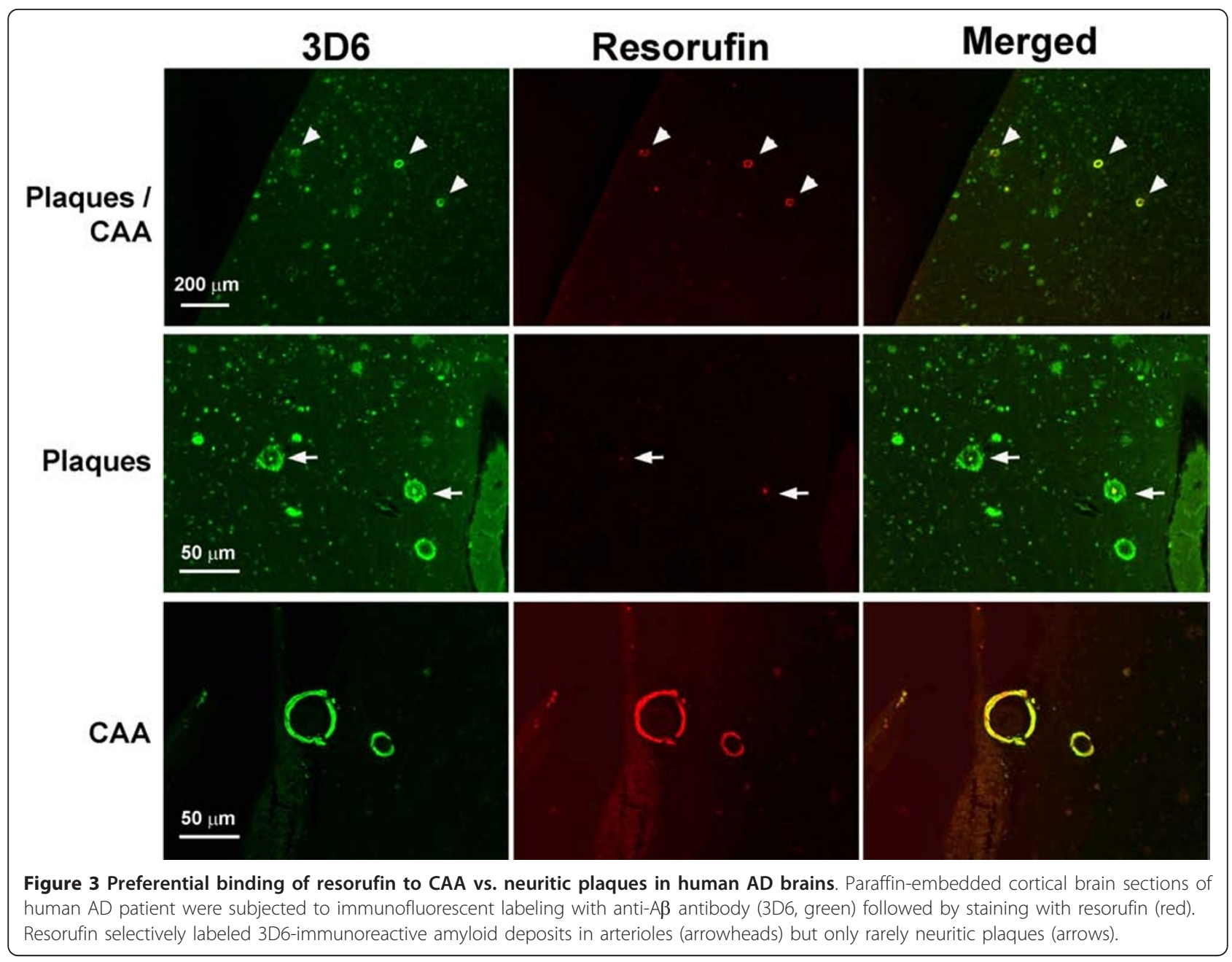

benzyloxy-resorufin: $\left.K_{D} 473 \pm 82 \mathrm{nM}\right)$. In contrast to resorufin analogs, methoxy-X34 bound almost equally to CAA deposits $\left(\mathrm{K}_{\mathrm{D}}: 325 \pm 39 \mathrm{nM}\right)$ and to neuritic plaques $\left(K_{\mathrm{D}}: 219 \pm 86 \mathrm{nM}\right)$.

\section{Discussion}

In the present study, we report three key findings: 1) that resorufin preferentially binds cerebrovascular A $\beta$ deposits over neuritic plaques in aged Tg2576 mouse brains as well as in human AD brains; 2) that resorufin staining colocalizes to a congophilic dye methoxy-X34 in close proximity to dystrophic smooth muscle cells of CAA-affected vessels; and 3) that resorufin can be modified to enhance lipophilicity, while preserving marked selectivity for cerebrovascular $A \beta$ deposits. These results indicate that the phenoxazine derivative resorufin and its derivatives are, to our knowledge, the first class of amyloid-imaging dyes that bind CAA in a highly selective manner. All previously described amyloid imaging ligands have been shown to bind CAA and neuritic plaques with similar affinity, making it very unlikely that these dyes could be used to develop PET imaging tracers appropriate for selective and definitive diagnosis of CAA in live patients. The unique selectivity of resorufin suggests that this class of dye has great potential as a CAA-specific amyloid tracer - the development of which would be a major diagnostic step forward for this frequent but often under-diagnosed condition.

Resorufin has been widely used as a fluorogenic probe to label bioactive molecules, and as an end-point product to measure hydrolytic activities of enzymes including peroxidases, cellulases, and aldehyde dehydrogenases. While examining the effect of CAA deposits on cerebrovascular oxidative stress, architecture, and function in aged Tg2576 mice, we initially observed that resorufin generated from Amplex red (a substrate for peroxidases) directly interacted with CAA independent of the status of oxidative stress in cerebral vessels. We characterized the cerebrovascular and parenchymal amyloid binding properties of resorufin and its derivatives ethoxy- and benzyloxy-resorufin. We found that the strongly fluorescent molecule resorufin 

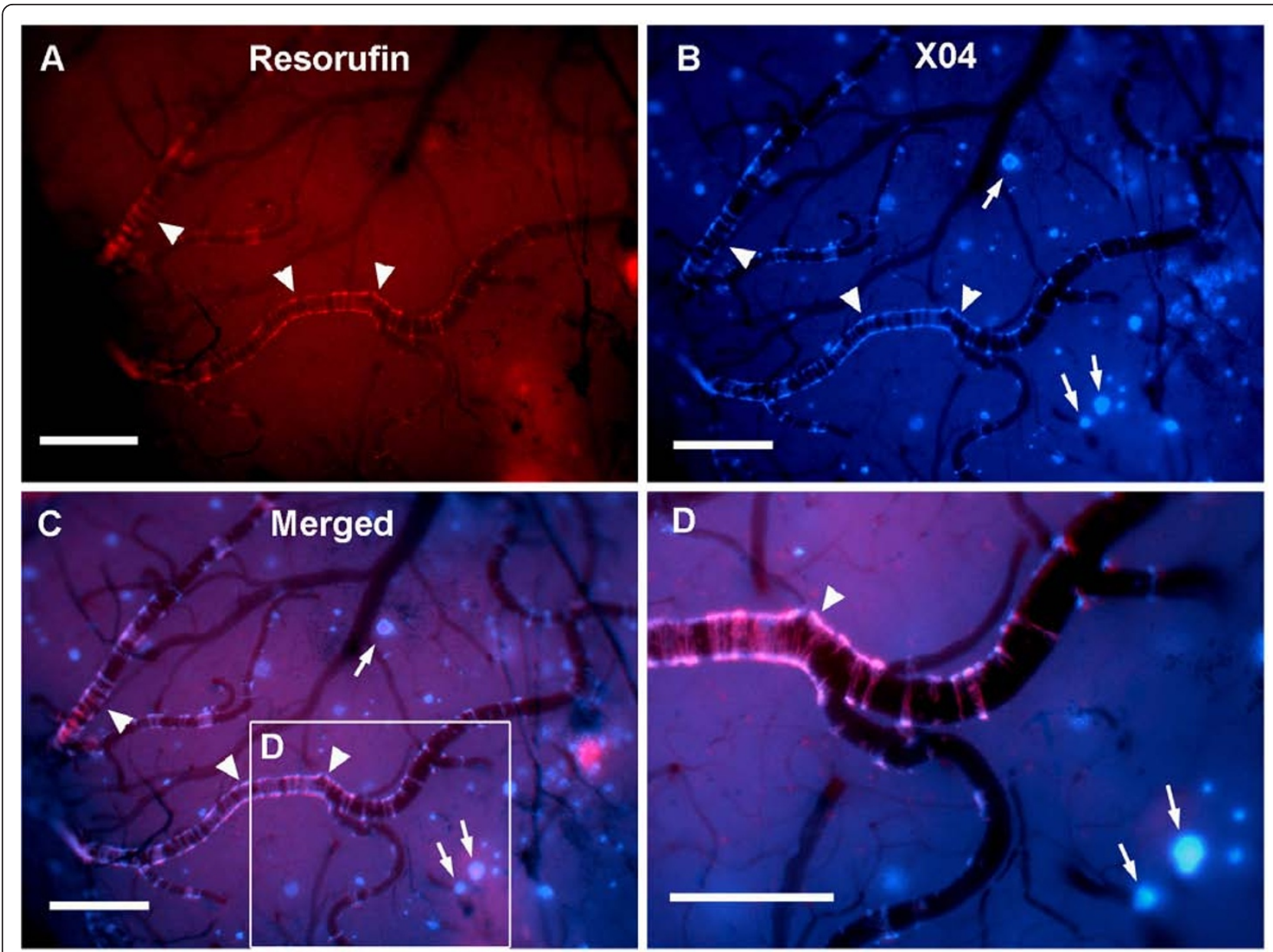

Figure 4 In vivo live imaging of CAA amyloid deposits through closed cranial window. Closed cranial windows were prepared on the right parietal bone of 16 month-old Tg2576 mice and the congophilic amyloid binding dye methoxy-X04 (X04) was administered (6 mg/kg i.p.). On the next day, $2 \mu \mathrm{M}$ resorufin (dissolved in artificial CSF) was superfused over the brain through a closed cranial window for 5 min. After washing with artificial CSF for 10 min, live fluorescent images of resorufin (red) and X04 (blue) were taken $(N=6)$. Resorufin selectively labels amyloid deposits in arterioles (arrowheads) but not neuritic plaques (arrows), whereas methoxy-X04 staining is present in both. Scale bars: 100 $\mu \mathrm{m}$.

preferentially bound cerebrovascular $A \beta$ aggregates over neuritic plaques when in situ staining was performed. In an independent study, Lebouvier et. al. [37] have reported that resorufin binds to neuritic plaques, neurofibrillary tangles, and CAA in postmortem AD brain sections. However, the resorufin concentration used in that study was 2000-fold higher than that used herein (2 $\mathrm{mM}$ vs. $1 \mu \mathrm{M}$ ) [37]. Non-selective binding of resorufin

\section{Table 1 Lipophilicity $\left(\log \mathrm{P}_{\text {oct }}\right)$ of resorufin analogs}

\begin{tabular}{ll}
\hline Compound name & ${ }^{\mathrm{a}}$ log $\mathbf{P}_{\text {oct }}$ \\
\hline Resorufin & $0.427 \pm 0.036$ \\
Ethoxyresorufin & $1.942 \pm 0.137$ \\
Benzyloxyresorufin & $2.206 \pm 0.104$ \\
Methoxy-X34 & ${ }^{b_{0}} 0.19$
\end{tabular}

${ }^{\mathrm{a}}$ Data represent mean \pm S.E.M from three independent experiments.

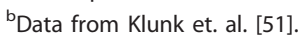

to $A \beta$ is expected at a high concentration; importantly, however, their study did not examine whether lower concentrations of resorufin detect $A \beta$ deposits differentially based on localization in cerebral vessels versus brain parenchyma. We observed markedly preferential binding to CAA when staining is performed with low concentrations of resorufin under stringent conditions (i.e., washing with PBS then with 50\% ethanol-containing PBS). This preferential binding for CAA cannot be attributed to artifact during brain tissue processing or fluorescent labeling since resorufin selectively visualized CAA deposits when directly applied onto the cortical surface of live Tg2576 mice (Figure 4).

Two critical conclusions stem from our observations. First, fluorescent imaging with resorufin can be a highly useful tool for the selective histopathological evaluation of CAA. For example, it is currently difficult to quantify 


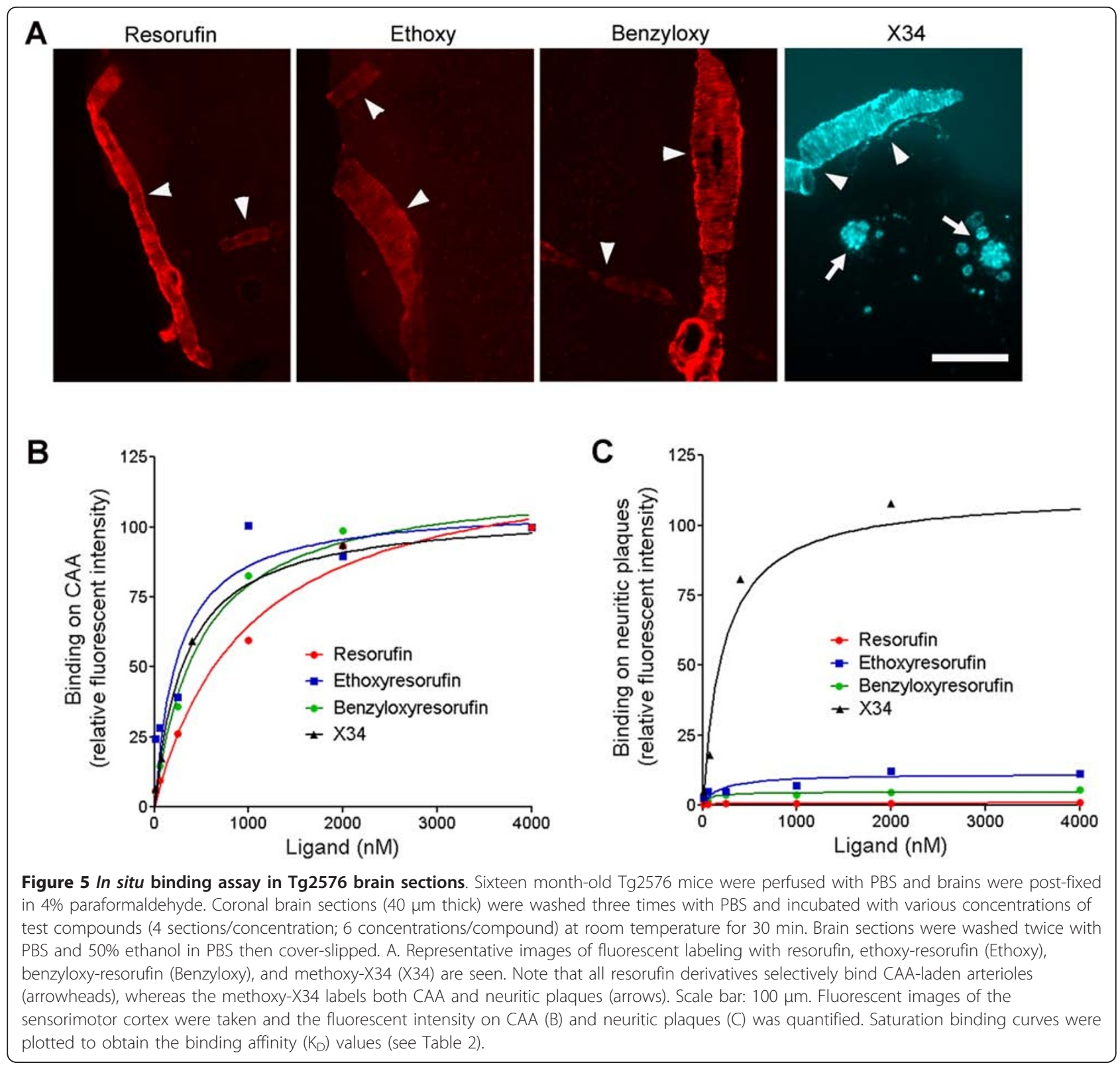

CAA versus neuritic plaque load using conventional amyloid dyes (e.g., thioflavin-S or Congo red analogs) due to their near equal affinity for vascular versus parenchymal $A \beta$ deposits. By exploiting the preferential binding properties of resorufin for cerebrovascular

Table 2 Amyloid binding affinities $\left(K_{D}\right)$ of resorufin analogs

\begin{tabular}{lll}
\hline Compound name & $\begin{array}{l}\text { On CAA } \\
\text { (nM) }\end{array}$ & $\begin{array}{l}\text { On neuritic } \\
\text { plaques (nM) }\end{array}$ \\
\hline Resorufin & $874 \pm 177$ & $>10,000$ \\
Ethoxyresorufin & $247 \pm 135$ & $>10,000$ \\
Benzyloxyresorufin & $473 \pm 82$ & $>10,000$ \\
Methoxy-X34 & $325 \pm 39$ & $219 \pm 86$ \\
\hline
\end{tabular}

amyloid plaques, this process of CAA quantification can be performed easily. Second, our data strongly suggest that the selective binding properties of resorufin can be exploited to eventually produce a CAA-specific amyloid tracer.

CAA is a strong and independent risk factor for cerebral hemorrhage, ischemic stroke and dementia in $\mathrm{AD}$ and non-AD patient populations [12-18]. Excitingly, recent preclinical studies have identified several novel approaches that reduce or even prevent CAA formation [38-41]. These studies raise the intriguing possibility that one or more of these CAA-directed therapeutic strategies might eventually be tested in humans. Unfortunately, such trials would currently be limited by the 
difficultly in diagnosing CAA: definitive diagnosis requires brain biopsy (which is rarely clinically indicated), and "probable" diagnosis of CAA by the Boston Criteria can be made only in patients who have already suffered intracerebral hemorrhage. Given that these bleeds occur less frequently $[19,42]$ and at a later stage [43] than ischemia, a trial using current diagnostics would be biased towards inclusion of later-stage CAA patients. The development of a non-invasive imaging technique for definitively diagnosing CAA would, in contrast, permit not only critical observational studies to better define the natural history of patients with CAA, but it would also greatly facilitate the organization and execution of therapeutic clinical trials that could include CAA patients who experience cerebral ischemia or dementia, not only hemorrhage.

To date, two chemically unrelated amyloid PET tracers, $\left[{ }^{11} \mathrm{C}\right] \mathrm{PIB}$ and $\left[{ }^{18} \mathrm{~F}\right]$ flobetapir, have demonstrated great promise as a tool for non-invasive amyloid imaging in patients with AD [25-32]. Importantly, however, these PET tracers are unable to discern whether the observed amyloid load represents neuritic plaques or CAA since they label both parenchymal and cerebrovascular amyloid deposits [44-46]. As such, our finding that resorufin analogs might represent a new class of PET agent for CAA-selective amyloid imaging is potentially groundbreaking. However, this must be considered in the context of well-described selection criteria for an ideal amyloid imaging PET tracer, including 1) high affinity and selectivity for target $A \beta$ aggregates; 2 ) low molecular weight (<400 g/mol); 3) moderate lipophilicity ( $\log \mathrm{P}_{\text {oct }}$ in a range of $\left.1-3\right)$; and 4 ) functional groups amenable to labeling with a positron-emitting radionucleotide such as ${ }^{11} \mathrm{C}$ or ${ }^{18} \mathrm{~F}$ - resorufin does not yet fulfill all of these requirements due to its low binding affinity for CAA $\left(\mathrm{K}_{\mathrm{D}}: 874 \mathrm{nM}\right)$ and low lipophilicity $\left(\log \mathrm{P}_{\text {oct }}\right.$ of 0.43 ) [22]. Nevertheless, our pilot structure-activity relationship data show that chemical modification at resorufin's phenol group is able to improve binding affinity for CAA and increase lipophilicity while maintaining its high selectivity for cerebrovascular $A \beta$ deposits. These results suggest that resorufin could serve as a lead compound to design chemical pools and to screen high-affinity, CAA-selective amyloid imaging dyes amenable to CAA imaging by PET.

Regarding the underlying mechanism by which resorufin analogs preferentially bind CAA over neuritic plaques, several potential explanations exist. One possibility is that resorufin binds fibrillar $\mathrm{A} \beta$ at different site(s) from other amyloid imaging dyes, a hypothesis that is supported by our observation that resorufin binding to CAA was not competitively inhibited by the congophilic dyes methoxy-X34 and methoxy-X04. A second possibility is that resorufin preferentially recognizes aggregations of $A \beta_{1-40}$ (the predominant species in CAA) over $A \beta_{1-42}$ (the predominant species in neuritic plaques). This hypothesis is supported by our observation that resorufin detects methoxy-X34-sensitive CAA from Tg2576 mice and humans (which is composed of both $A \beta_{1-40}$ and $A \beta_{1-42}[6,47]$ ) (Figures 1 and 3), but does not detect methoxy-X34-sensitive CAA from BRI$A \beta 42$ transgenic mouse (which is composed almost exclusively of $A \beta_{1-42}$ [5]) (data not shown). A third possibility is that resorufin directly interacts with molecules or proteins that are present in CAA but not in neuritic plaques. For example, heparan sulfate proteoglycans are expressed much more highly in cerebrovascular deposits as compared to neuritic plaques, both in human AD brains and in HCHWA-D mice carrying the Dutch-type amyloidosis $[48,49]$. Further investigation is required to elucidate the underlying mechanism by which resorufin preferentially binds CAA over neuritic plaques - the identification of which will not only shed new light on CAA pathophysiology but may also lead to novel therapeutic targets that could be exploited to help prevent CAA formation and its neurological consequences.

\section{Conclusions}

In summary, to our knowledge, this is the first report demonstrating that resorufin has high selective affinity for cerebrovascular $A \beta$ aggregates over neuritic plaques in fixed brain tissues and in live APP transgenic mice. Resorufin analogs modified at the $7-\mathrm{OH}$ position demonstrated enhanced lipophilicity while retaining their high binding affinity for cerebrovascular $A \beta$ aggregates. These results suggest that resorufin analogs are promising potential tracers for CAA-selective imaging, as opposed to conventional amyloid imaging ligands that non-selectively bind both CAA deposits and neuritic plaques. Further studies are warranted to determine whether positron-emitting radioligands such as $\left[{ }^{11} \mathrm{C}\right]$ - or $\left[{ }^{18} \mathrm{~F}\right]$-labeled resorufin analogs are feasible for use as CAA-selective PET or SPECT imaging tracers in experimental mouse models and in humans.

\section{Methods}

\section{Animals and materials}

All experimental protocols were approved by the Animal Studies Committee at Washington University. The production, genotyping, and background strain (B6/SJL) of Tg2576 mice used in this study have been described previously [33,35,50]. Tg2576 mice overexpressing human APP695 with the familial Swedish AD mutations at positions 670/671 under control of the hamster prion protein (PrP) promoter were a generous gift from Dr. K. Ashe (University of Minnesota, Minneapolis, MN). Resorufin, ethoxy-resorufin, benzyloxy-resorufin, and octanol were purchased from Sigma-Aldrich (St. Louis, 
MO). Amyloid imaging dyes methoxy-X04 and methoxy-X34 were synthesized as described previously [51].

\section{Fluorescent labeling and quantification of CAA and neuritic plaque loads in Tg2576 brain sections}

Tg2576 and littermate wild-type mice at 12-16 months of age were anesthetized with isoflurane and transcardially perfused with PBS. Brains were removed, postfixed overnight in $4 \%$ paraformaldehyde in $0.1 \mathrm{M}$ phosphate buffer $(\mathrm{pH} 7.4)$ at $4^{\circ} \mathrm{C}$, and preserved in $30 \%$ sucrose in $0.1 \mathrm{M}$ phosphate buffer at $4^{\circ} \mathrm{C}$. Brains were sectioned coronally $(40 \mu \mathrm{m})$ on a freezing sliding microtome as described previously [52]. To label brain sections with resorufin and methoxy-X34, fixed brain tissues ( 4 sections/brain) were washed three times with PBS and permeabilized by incubating in PBS containing $0.25 \%$ Triton-X100 (PBS-T) at room temperature for 30 min. Brain sections were stained with PBS-T containing $1 \mu \mathrm{M}$ resorufin and $2 \mu \mathrm{M}$ methoxy-X34 at room temperature for $30 \mathrm{~min}$. Brain sections were washed three times with PBS and once with $50 \%$ ethanol in PBS for 5 min each. After three more PBS washes, brain sections were mounted on a slide glass and cover-slipped with Vectashield mounting media (Vector laboratories, Burlingame, CA). Fluorescent staining was visualized using a Nikon Eclipse ME600 digital video microscopy system (Nikon Instruments Inc., Melville, NY) and MetaMorph imaging software (Molecular Devices, Sunnyvale, CA). Cross-sectional area covered by CAA vessels and parenchymal plaques were quantified using ImageJ software (National Institutes of Health, Bethesda, MD) as previously described [6].

Triple labeling and multi-photon microscopy

Vascular smooth muscle cells and CAA deposition was assessed as previously reported [35] with modification. Paraformaldehyde-fixed whole brains were permeabilized with PBS-T for $20 \mathrm{~min}$ at room temperature, and then incubated with PBS-T containing $1 \mu \mathrm{M}$ resorufin and $2 \mu \mathrm{M}$ methoxy-X34 for $30 \mathrm{~min}$ at room temperature. Brains were washed three times with PBS and once with $50 \%$ ethanol in PBS for 5 min each. Brains were blocked with $2 \%$ bovine serum albumin (BSA) in PBS-T for $30 \mathrm{~min}$, followed by incubation with phalloidinAlexa-488 (Invitrogen, Carlsbad, CA) in PBS containing $1 \%$ BSA. Fluorescent staining with phalloidin-Alexa488, resorufin and methoxy-X34 was simultaneously imaged using a Zeiss LSM 510 META LNO two-photon microscope (Carl Zeiss, Jena, Germany).

Immunofluorescent labeling in human AD brain sections Paraffin-embedded postmortem brain sections prepared from patients with $\mathrm{AD}$ were provided by the Alzheimer's
Disease Research Center at Washington University. Brain tissues (10 $\mu \mathrm{m}$ thick) were deparaffinized with xylene and rehydrated by incubation with $100-70 \%$ ethanol and PBS. Brain sections were blocked with buffer (PBS-BB) containing 0.1\% Triton-X 100, 0.2\% dry milk and $1 \%$ BSA serum in PBS at room temperature for $1 \mathrm{~h}$. To label fibrillar amyloid, sections were then incubated with biotinylated anti-A $\beta$ antibody 3D6 (dilution: 1:3000, a generous gift from Dr. David M. Holtzman) overnight at $4^{\circ} \mathrm{C}$. After washing with $\mathrm{PBS}$, sections were incubated with streptavidin-Alexa 488 (Invitrogen, Carlsbad, CA), followed by labeling with $1 \mu \mathrm{M}$ resorufin as described above. Sections were rinsed with PBS, cover-slipped and subjected to fluorescent microscopy.

\section{Closed cranial window preparation and live microscopic imaging}

A closed cranial window preparation was performed as previously reported [35]. Briefly, mice were anesthetized with isoflurane ( $4 \%$ induction, $1.5 \%$ maintenance), and a 4-mm diameter craniotomy was performed with a water-cooled dental drill in the right parietal bone. Two silastic tubings (ID: $0.3 \mathrm{~mm}$, OD: $0.64 \mathrm{~mm}$; Dow Corning, Midland, MI) were inserted through the bone wax to permit topical application of vasodilators. The craniotomy was filled with artificial cerebrospinal fluid (aCSF) and sealed to the bone with a microscope coverglass using dental cement. To label amyloid deposits in the brain, mice were administered BBB-permeable Congo red derivative methoxy-X04 (6 $\mathrm{mg} / \mathrm{kg}$ i.p.) as described [35]. Fifteen hours later, mice were re-anesthetized with isoflurane and $\alpha$-chloralose, and ventilated. Fluorescent images were visualized using a Nikon Eclipse $600 \mathrm{ME}$ digital video microscopy system. To label CAA, aCSF containing $1 \mu \mathrm{M}$ resorufin was infused into the cranial window at a rate of $20 \mu \mathrm{l} / \mathrm{min}$ for $5 \mathrm{~min}$. After washing with aCSF for $10 \mathrm{~min}$, fluorescent resorufin and methoxy-X04 images were taken.

\section{Determination of lipophilicity ( $\left.\log \mathrm{P}_{\text {oct }}\right)$}

Octanol-water partition coefficients $\left(\log \mathrm{P}_{\text {oct }}\right)$ were determined as described previously with modification [53]. An equal volume $(600 \mu \mathrm{l})$ of $n$-octanol (Sigma-Aldrich, St. Louis, MO) and distilled water were added to a microcentrifuge tube, followed by an addition of resorufin analogues at a final concentration of $100 \mu \mathrm{M}$. The samples were incubated at room temperature with a brief vortex every $5 \mathrm{~min}$ for 60 minutes. After centrifugation at 2,000 $\mathrm{g}$ for $10 \mathrm{~min}$, octanol and water layers were separately transferred to microcentrifuge tubes. Concentrations were determined by fluorometry at an excitation wave length of 530/25 $\mathrm{nm}$ and an emission 
wave length of 590/30 $\mathrm{nm}$ using an ELISA reader (Biotek, Winooski, VT).

\section{List of abbreviations used}

AD: Alzheimer's disease; CAA: cerebral amyloid angiopathy; PET: positron emission tomography; VSMC: vascular smooth muscle cell; PBS: phosphatebuffered saline; PBS-T: PBS containing 0.25\% Triton-X100; aCSF: artificial cerebrospinal fluid.

\section{Acknowledgements}

The authors thank Guangyi Ling, Min Yoo, Tej Azad and Michael Harries for their technical assistance, as well as Washington University's Alzheimer's Disease Research Center (ADRC) for human pathological specimens. This work was supported by grants from the American Health Assistance Foundation (BHH), Washington University Hope Center and ADRC, and in part by National Institutes of Health Grant 1RO1NS071011 (GJZ).

\section{Author details}

'Department of Neurological Surgery, Washington University School of Medicine, St. Louis, MO 63110, USA. ${ }^{2}$ Hope Center for Neurological Disorders, Washington University School of Medicine, St. Louis, MO 63110, USA. ${ }^{3}$ Program in Neuroscience, Washington University Division of Biology and Biomedical Sciences, St. Louis, MO 63110, USA. ${ }^{4}$ Division of Radiological Sciences, Washington University School of Medicine, St. Louis, MO 63110, USA. ${ }^{5}$ Department of Neurology, Washington University School of Medicine, St. Louis, MO 63110, USA.

\section{Authors' contributions}

$\mathrm{BHH}$ contributed to the general administration and direction of the project, interpretation of experimental results, and development and writing of the manuscript. MLZ performed live fluorescent imaging. AKV performed multiphoton imaging in fixed brain sections and image processing, and writing of the manuscript. EM contributed to fluorescent imaging, statistical data analysis, and writing the manuscript. DHK performed the fluorescent ligand binding assays. JKG performed the CAA load and neuritic plaque load analyses. WC contributed to the experimental design for structure-activity relationship of test compounds. RHM contributed to the overall design of chemical modification and review of data. GJZ contributed to direction of the project, interpretation of experimental results, and critical reviewing of the manuscript. All authors read and approved the final manuscript.

\section{Competing interests}

$\mathrm{BHH}, \mathrm{WC}, \mathrm{RHM}$ and GJZ have patent applications on the composition, methods, and use related to resorufin derivatives. The authors declare that they have no competing interests.

Received: 10 October 2011 Accepted: 22 December 2011 Published: 22 December 2011

\section{References}

1. Sisodia SS: Alzheimer's disease: perspectives for the new millennium. $J$ Clin Invest 1999, 104:1169-1170.

2. Zhang YW, Xu H: Molecular and Cellular Mechanisms for Alzheimer's Disease: Understanding APP Metabolism. Curr Mol Med 2007, 7:687-696.

3. Selkoe DJ: Alzheimer's disease: genes, proteins, and therapy. Physiol Rev 2001, 81:741-766.

4. Kim J, Onstead L, Randle S, Price R, Smithson L, Zwizinski C, Dickson DW, Golde T, McGowan E: Abeta40 inhibits amyloid deposition in vivo. $J$ Neurosci 2007, 27:627-633.

5. McGowan E, Pickford F, Kim J, Onstead L, Eriksen J, Yu C, Skipper L, Murphy MP, Beard J, Das P, Jansen K, Delucia M, Lin WL, Dolios G, Wang R, Eckman CB, Dickson DW, Hutton M, Hardy J, Golde T: Abeta42 is essential for parenchymal and vascular amyloid deposition in mice. Neuron 2005, 47:191-199.

6. Fryer JD, Simmons K, Parsadanian M, Bales KR, Paul SM, Sullivan PM, Holtzman DM: Human apolipoprotein E4 alters the amyloid-beta 40:42 ratio and promotes the formation of cerebral amyloid angiopathy in an amyloid precursor protein transgenic model. J Neurosci 2005, $25 \cdot 2803-2810$
7. McCarron MO, Nicoll JA, Stewart J, Cole GM, Yang F, Ironside JW, Mann DM Love S, Graham Dl: Amyloid beta-protein length and cerebral amyloid angiopathy-related haemorrhage. Neuroreport 2000, 11:937-940.

8. Domnitz SB, Robbins EM, Hoang AW, Garcia-Alloza M, Hyman BT, Rebeck GW, Greenberg SM, Bacskai BJ, Frosch MP: Progression of cerebral amyloid angiopathy in transgenic mouse models of Alzheimer disease. $J$ Neuropathol Exp Neurol 2005, 64:588-594.

9. Herzig MC, Winkler DT, Burgermeister P, Pfeifer M, Kohler E, Schmidt SD, Danner S, Abramowski D, Sturchler-Pierrat C, Burki K, van Duinen SG, MaatSchieman ML, Staufenbiel M, Mathews PM, Jucker M: Abeta is targeted to the vasculature in a mouse model of hereditary cerebral hemorrhage with amyloidosis. Nat Neurosci 2004, 7:954-960.

10. Maia LF, Mackenzie IR, Feldman HH: Clinical phenotypes of Cerebral Amyloid Angiopathy. J Neurol Sci 2007, 257:23-30.

11. Nicoll JA, Yamada M, Frackowiak J, Mazur-Kolecka B, Weller RO: Cerebral amyloid angiopathy plays a direct role in the pathogenesis of Alzheimer's disease. Pro-CAA position statement. Neurobiol Aging 2004, 25:589-597, discussion 603-584.

12. Vinters HV: Cerebral amyloid angiopathy. A critical review. Stroke 1987, 18:311-324.

13. Greenberg SM: Cerebral amyloid angiopathy and vessel dysfunction. Cerebrovasc Dis 2002, 13(Suppl 2):42-47.

14. Okazaki H, Reagan TJ, Campbell RJ: Clinicopathologic studies of primary cerebral amyloid angiopathy. Mayo Clin Proc 1979, 54:22-31.

15. Greenberg SM, Vonsattel JP, Stakes JW, Gruber M, Finklestein SP: The clinical spectrum of cerebral amyloid angiopathy: presentations without lobar hemorrhage. Neurology 1993, 43:2073-2079.

16. Vermeer SE, Prins ND, den Heijer T, Hofman A, Koudstaal PJ, Breteler MM: Silent brain infarcts and the risk of dementia and cognitive decline. $N$ Engl J Med 2003, 348:1215-1222.

17. Itoh Y, Yamada M: Cerebral amyloid angiopathy in the elderly: the clinicopathological features, pathogenesis, and risk factors. Journal of medical and dental sciences 1997, 44:11-19.

18. Mann DM, Iwatsubo T, Ihara Y, Cairns NJ, Lantos PL, Bogdanovic N, Lannfelt L, Winblad B, Maat-Schieman ML, Rossor MN: Predominant deposition of amyloid-beta 42(43) in plaques in cases of Alzheimer's disease and hereditary cerebral hemorrhage associated with mutations in the amyloid precursor protein gene. Am J Pathol 1996, 148:1257-1266.

19. Knudsen KA, Rosand J, Karluk D, Greenberg SM: Clinical diagnosis of cerebral amyloid angiopathy: validation of the Boston criteria. Neurology 2001, 56:537-539.

20. Lee VM: Amyloid binding ligands as Alzheimer's disease therapies. Neurobiol Aging 2002, 23:1039-1042.

21. Suhara T, Higuchi M, Miyoshi M: Neuroimaging in dementia: in vivo amyloid imaging. The Tohoku journal of experimental medicine 2008, 215:119-124.

22. Henriksen G, Yousefi BH, Drzezga A, Wester HJ: Development and evaluation of compounds for imaging of beta-amyloid plaque by means of positron emission tomography. European journal of nuclear medicine and molecular imaging 2008, 35(Suppl 1):S75-81.

23. Nordberg A: Amyloid imaging in Alzheimer's disease. Current opinion in neurology 2007, 20:398-402.

24. Nordberg A: Amyloid plaque imaging in vivo: current achievement and future prospects. European journal of nuclear medicine and molecular imaging 2008, 35(Suppl 1):S46-50.

25. Klunk WE, Engler H, Nordberg A, Wang Y, Blomqvist G, Holt DP, Bergstrom M, Savitcheva I, Huang GF, Estrada S, Ausen B, Debnath ML, Barletta J, Price JC, Sandell J, Lopresti BJ, Wall A, Koivisto P, Antoni G, Mathis CA, Langstrom B: Imaging brain amyloid in Alzheimer's disease with Pittsburgh Compound-B. Ann Neurol 2004, 55:306-319.

26. Archer HA, Edison P, Brooks DJ, Barnes J, Frost C, Yeatman T, Fox NC, Rossor MN: Amyloid load and cerebral atrophy in Alzheimer's disease: an 11C-PIB positron emission tomography study. Ann Neurol 2006, 60:145-147.

27. Kemppainen NM, Aalto S, Wilson IA, Nagren K, Helin S, Bruck A, Oikonen V, Kailajarvi M, Scheinin M, Viitanen M, Parkkola R, Rinne JO: Voxel-based analysis of PET amyloid ligand [11C]PIB uptake in Alzheimer disease. Neurology 2006, 1575-1580

28. Mintun MA, Larossa GN, Sheline YI, Dence CS, Lee SY, Mach RH, Klunk WE, Mathis CA, DeKosky ST, Morris JC: [11C]PIB in a nondemented population: 
potential antecedent marker of Alzheimer disease. Neurology 2006, 67:446-452.

29. Engler H, Forsberg A, Almkvist O, Blomquist G, Larsson E, Savitcheva I, Wall A, Ringheim A, Langstrom B, Nordberg A: Two-year follow-up of amyloid deposition in patients with Alzheimer's disease. Brain 2006 129:2856-2866.

30. Choi SR, Golding G, Zhuang Z, Zhang W, Lim N, Hefti F, Benedum TE, Kilbourn MR, Skovronsky D, Kung HF: Preclinical properties of 18F-AV-45: a PET agent for Abeta plaques in the brain. J Nucl Med 2009, 50:1887-1894.

31. Wong DF, Rosenberg PB, Zhou Y, Kumar A, Raymont V, Ravert HT, Dannals RF, Nandi A, Brasic JR, Ye W, Hilton J, Lyketsos C, Kung HF, Joshi AD, Skovronsky DM, Pontecorvo MJ: In vivo imaging of amyloid deposition in Alzheimer disease using the radioligand 18F-AV-45 (florbetapir [corrected] F 18). J Nucl Med 2010, 51:913-920.

32. Clark CM, Schneider JA, Bedell BJ, Beach TG, Bilker WB, Mintun MA, Pontecorvo MJ, Hefti F, Carpenter AP, Flitter ML, Krautkramer MJ, Kung HF, Coleman RE, Doraiswamy PM, Fleisher AS, Sabbagh MN, Sadowsky CH, Reiman EP, Reiman PEM, Zehntner SP, Skovronsky DM, Group AAS: Use of florbetapir-PET for imaging beta-amyloid pathology. JAMA 2011, 305:275-283.

33. Hsiao K, Chapman P, Nilsen S, Eckman C, Harigaya Y, Younkin S, Yang F, Cole G: Correlative memory deficits, Abeta elevation, and amyloid plaques in transgenic mice. Science 1996, 274:99-102.

34. Kawarabayashi T, Younkin LH, Saido TC, Shoji M, Ashe KH, Younkin SG: Agedependent changes in brain, CSF, and plasma amyloid (beta) protein in the Tg2576 transgenic mouse model of Alzheimer's disease. J Neurosci 2001, 21:372-381.

35. Han BH, Zhou ML, Abousaleh F, Brendza RP, Dietrich HH, KoenigsknechtTalboo J, Cirrito JR, Milner E, Holtzman DM, Zipfel GJ: Cerebrovascular dysfunction in amyloid precursor protein transgenic mice: contribution of soluble and insoluble amyloid-beta peptide, partial restoration via gamma-secretase inhibition. J Neurosci 2008, 28:13542-13550.

36. Mathis CA, Bacskai BJ, Kajdasz ST, McLellan ME, Frosch MP, Hyman BT, Holt DP, Wang Y, Huang GF, Debnath ML, Klunk WE: A lipophilic thioflavin-T derivative for positron emission tomography (PET) imaging of amyloid in brain. Bioorganic \& medicinal chemistry letters 2002 12:295-298.

37. Lebouvier T, Perruchini C, Panchal M, Potier MC, Duyckaerts C: Cholesterol in the senile plaque: often mentioned, never seen. Acta neuropathologica 2009, 117:31-34.

38. Hawkes CA, McLaurin J: Selective targeting of perivascular macrophages for clearance of beta-amyloid in cerebral amyloid angiopathy. Proc Natl Acad Sci USA 2009, 106:1261-1266.

39. Prada CM, Garcia-Alloza M, Betensky RA, Zhang-Nunes SX, Greenberg SM, Bacskai BJ, Frosch MP: Antibody-mediated clearance of amyloid-beta peptide from cerebral amyloid angiopathy revealed by quantitative in vivo imaging. J Neurosci 2007, 27:1973-1980

40. Racke MM, Boone LI, Hepburn DL, Parsadainian M, Bryan MT, Ness DK, Piroozi KS, Jordan WH, Brown DD, Hoffman WP, Holtzman DM, Bales KR, Gitter BD, May PC, Paul SM, DeMattos RB: Exacerbation of cerebral amyloid angiopathy-associated microhemorrhage in amyloid precursor protein transgenic mice by immunotherapy is dependent on antibody recognition of deposited forms of amyloid beta. J Neurosci 2005, 25:629-636.

41. Schroeter S, Khan K, Barbour R, Doan M, Chen M, Guido T, Gill D, Basi G, Schenk D, Seubert P, Games D: Immunotherapy reduces vascular amyloid-beta in PDAPP mice. J Neurosci 2008, 28:6787-6793.

42. Kimberly WT, Gilson A, Rost NS, Rosand J, Viswanathan A, Smith EE, Greenberg SM: Silent ischemic infarcts are associated with hemorrhage burden in cerebral amyloid angiopathy. Neurology 2009, 72:1230-1235.

43. Zipfel GJ, Han H, Ford AL, Lee JM: Cerebral Amyloid Angiopathy. Progressive Disruption of the Neurovascular Unit. Stroke 2008.

44. Lin KJ, Hsu WC, Hsiao IT, Wey SP, Jin LW, Skovronsky D, Wai YY, Chang HP, Lo CW, Yao CH, Yen TC, Kung MP: Whole-body biodistribution and brain PET imaging with [18F]AV-45, a novel amyloid imaging agent-a pilot study. Nuclear medicine and biology 2010, 37:497-508.

45. Ly JV, Donnan GA, Villemagne VL, Zavala JA, Ma H, O'Keefe G, Gong SJ, Gunawan RM, Saunder T, Ackerman U, Tochon-Danguy H, Churilov L, Phan TG, Rowe CC: 11C-PIB binding is increased in patients with cerebral amyloid angiopathy-related hemorrhage. Neurology 2010, 74:487-493.
46. Yates PA, Sirisriro R, Villemagne VL, Farquharson S, Masters CL, Rowe CC: Cerebral microhemorrhage and brain beta-amyloid in aging and Alzheimer disease. Neurology 2011, 77:48-54.

47. Herzig MC, Van Nostrand WE, Jucker M: Mechanism of cerebral betaamyloid angiopathy: murine and cellular models. Brain Pathol 2006, 16:40-54.

48. van Horssen J, Otte-Holler I, David G, Maat-Schieman ML, van den Heuvel LP, Wesseling P, de Waal RM, Verbeek MM: Heparan sulfate proteoglycan expression in cerebrovascular amyloid beta deposits in Alzheimer's disease and hereditary cerebral hemorrhage with amyloidosis (Dutch) brains. Acta neuropathologica 2001, 102:604-614

49. Timmer NM, Schirris TJJ, Bruinsma IB, Otte-Holler I, van Kuppevelt TH, de Waal RMW, Verbeek MM: Aggregation and cytotoxic properties towards cultured cerebrovascular cells of Dutch-mutated Abeta40 (DAbeta(1-40)) are modulated by sulfate moieties of heparin. Neurosci Res 2010, 66:380-389.

50. Holtzman DM, Fagan AM, Mackey B, Tenkova T, Sartorius L, Paul SM, Bales $\mathrm{K}$, Ashe KH, Irizarry MC, Hyman BT: Apolipoprotein E facilitates neuritic and cerebrovascular plaque formation in an Alzheimer's disease model. Ann Neurol 2000, 47:739-747.

51. Klunk WE, Bacskai BJ, Mathis CA, Kajdasz ST, McLellan ME, Frosch MP, Debnath ML, Holt DP, Wang Y, Hyman BT: Imaging Abeta plaques in living transgenic mice with multiphoton microscopy and methoxy-X04, a systemically administered Congo red derivative. J Neuropathol Exp Neurol 2002, 61:797-805.

52. Han BH, D'Costa A, Back SA, Parsadanian M, Patel S, Shah AR, Gidday JM, Srinivasan A, Deshmukh M, Holtzman DM: BDNF blocks caspase-3 activation in neonatal hypoxia-ischemia. Neurobiol Dis 2000, 7:38-53.

53. Ryu EK, Choe YS, Lee KH, Choi Y, Kim BT: Curcumin and dehydrozingerone derivatives: synthesis, radiolabeling, and evaluation for beta-amyloid plaque imaging. Journal of medicinal chemistry 2006, 49:6111-6119.

doi:10.1186/1750-1326-6-86

Cite this article as: Han et al:: Resorufin analogs preferentially bind cerebrovascular amyloid: potential use as imaging ligands for cerebral amyloid angiopathy. Molecular Neurodegeneration 2011 6:86.

\section{Submit your next manuscript to BioMed Central and take full advantage of:}

- Convenient online submission

- Thorough peer review

- No space constraints or color figure charges

- Immediate publication on acceptance

- Inclusion in PubMed, CAS, Scopus and Google Scholar

- Research which is freely available for redistribution

Submit your manuscript at www.biomedcentral.com/submit
Ciomed Central 